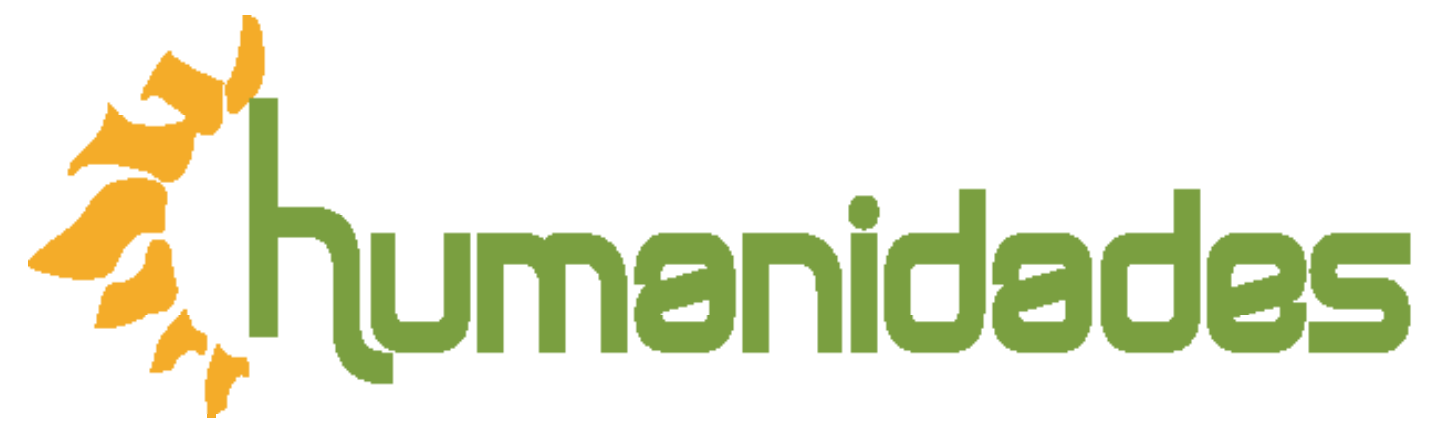

Revista de la Escuela de Estudios Generales, Universidad de Costa Rica

Julio-diciembre, 2019 •Volumen 9, número 2・EISSN 2215-3934・pp. 1-12

Recibido: 04-Febrero-2019 Aceptado: 10-Febrero-2019

\title{
Arte y dataísmo: afirmándonos desde las pantallas
}

DOI: https://doi.org/10.15517/h.v9i2.37097

\section{Isabel Gaspar Robles}

Universidad Nacional Autónoma de México (UNAM), México

Correo electrónico: gaspar.isabelr@gmail.com

Todos los derechos reservados. Universidad de Costa Rica. Esta revista se encuentra licenciada con Creative Commons. Reconocimiento-NoComercial-SinObraDerivada 3.0 Costa Rica. Correo electrónico: humanidades@ucr.ac.cr/ Sitio web: http: //revistas.ucr.ac.cr/index.php/ humanidades 


\title{
Arte y dataísmo: afirmándonos desde las pantallas
}

\section{Resumen}

Cuando hemos perdido la fe en la realidad de la vida y solo creemos, como dice

Palabras clave:

Berardi en el prólogo de Los condenados de la pantalla, en la proliferación infinita de imágenes (Steyerl, 2014, p. 12), ¿qué nos queda?, ¿cuáles son las nuevas deidades?, ¿en quién o en qué creemos?; se podría afirmar que en todo aquello que sea capaz de entregarnos, producir y reproducir imágenes.

Si las imágenes son nuestras nuevas creencias, y las pantallas —es decir, aquello que nos permite acercarnos a las "creencias" — son nuestras nuevas deidades, es necesario tomar desde ellas una postura política ante el mundo, sobre todo desde la producción artística y de los estudios visuales. Este artículo reflexiona las posturas de algunos artistas que trabajan con las imágenes a través de las pantallas, como es el caso de Ryoji Ikeda, David Horvitz y Pussy Riot, y presenta la pantalla y sus interfaces como el archivo histórico de lo que sucede hoy en la sociedad.

\section{Art and Dataism: Establishing Ourselves Through the Digital Screens}

\begin{abstract}
When we have lost faith in reality and only believe, as Berardi states in the preface of Los condenados de la pantalla, in the infinite proliferation of images (Steyerl, 2014, p. 12), what do we have left? Who are the new deities? In whom or in what do we believe? We could affirm that in anything that will deliver, produce, and reproduce images.

If images are our new objects of belief, and digital screens (which permit us to approach beliefs) are our new deities, it becomes necessary to employ them in order to take a political stance before the world, especially in the field of art production and visual studies. This paper examines the positions of several artists, such as Ryoji Ikeda, David Horvitz, and Pussy Riot, who work with on-screen images. This paper also considers the digital screen and its interfaces the historical archive of the events of contemporary society.
\end{abstract}

Keywords:

pictures, information technology, art, codes 
Arte y dataísmo: afirmándonos desde las pantallas

\section{Interfaces, imágenes y pantallas}

La experiencia en la actualidad está mediada por las pantallas. Lo que vemos en ellas es la intersección entre conocimiento, imaginación, información y tecnología. Todo lo que vemos, hacemos y conocemos ha sido visto antes a través de una pantalla. Cuando vamos a conocer algún nuevo lugar, la mayoría de las veces ya lo hemos buscado en Google e incluso hemos solicitado opiniones. Casi cualquier cosa que hagamos podemos encontrarla previamente en internet $\mathrm{y}$, si no es así, nos aseguraremos de que el mundo sepa que estuvimos ahí o que hicimos eso y quedará registrado en Instagram, Facebook, Twitter o cualquiera que sea nuestra red social favorita.

Las imágenes son pulsos eléctricos que generan un dinamismo al ser intercambiadas entre pantallas. Las imágenes son códigos, ceros y unos, datos traducidos por interfaces, por esto es importante no solo lo que vemos en la imagen, sino también la extracción de los datos y la huella que esto genera.

Es a través de las interfaces que podemos ver la información traducida en imágenes o en formatos mucho más perceptibles por nosotros; las interfaces son las que traducen los ceros y los unos. Pero una interfaz no es solamente el objeto tecnológico que permite esto: en la actualidad, se ha convertido en un "espacio virtual" en el que suceden interacciones y dinámicas. Todo tipo de tecnología genera cambios y transformaciones, y la interfaz ha generado, sin duda, masivas transformaciones políticas, económicas, sociales y culturales, pero no solamente ha creado estas transformaciones, sino que también ha participado en registrar y compartir esas mismas transformaciones. El movimiento de imágenes y datos en tiempo real significa que ya no podemos ser localizados solamente en un lugar físico. Es decir, el mundo puede ser reestructurado desde los datos como contexto de la información a través de las imágenes y así la percepción de la realidad, del mundo, de la imagen $\mathrm{y}$, por tanto, de la cultura sufre transformaciones trascendentales como lo señala Soren Bro Pold: 
Es mi punto de vista que podemos reconocer este impacto a través del arte digital: cómo la interfaz cambia lo que vemos y cómo lo vemos, cómo experimentamos e interactuamos con la realidad y cómo esta realidad se reconfigura a través de la computadora. El arte digital en general nos muestra el rol de la interfaz y su significado como un objeto estético, cultural e ideológico [traducción propia]. (2005, p. 11) ${ }^{1}$

Vivimos la realidad a partir de la imagen mediatizada en una sociedad hiperconectada 24/7, visualmente capitalista, bajo los parámetros de los datos. Las imágenes circulan infinitamente, y es por la interfaz que podemos ver, distribuir, compartir, descargar y modificar estas imágenes. En un artículo de Parker A. (2011) se menciona cómo Jacob Eisenstein, haciendo referencia a los tweets, dijo: "probablemente no crees en el mensaje porque en lo que realmente crees es en el hashtag [traducción propia]". Si lo parafraseamos podemos tener la misma idea sobre las imágenes: probablemente ya no crees en la imagen porque en lo que realmente crees es en el hashtag. El hashtag constituye, en este caso, parte de la interfaz, el metadato, la dinámica de lo que sucede entre la pantalla, la información y el usuario.

La imagen se ha convertido en algo natural en nuestro mundo, en un referente constante en nuestra mirada. Resulta una constante antropológica actual que nos hace preguntarnos, entonces, ¿qué significa comprometerse con los mundosimágenes? Las imágenes se han vuelto el contexto del usuario, parte de los nuevos lenguajes, de las narrativas no lineales. Las imágenes dejan de ser representaciones de algo y son meramente traducciones de códigos, nada aspira a la mimesis ya, "aquí la imagen no mira al mundo, no se pretende pintura, pero tampoco a los ojos de quien la observa (...) aquí todo es pura actividad, digitación, expresión, fábrica, superficie y gestión de efectos” (Brea, 2010, p. 81). Pero las imágenes también son traducciones de acciones humanas, mediadoras y creadoras de dinámicas entre humano-humano y entre humano-máquina a través de las interfaces. "Las imágenes son las interfaces que estructuran la interacción, a la gente y los entornos que comparten [traducción propia]"2 (Burnett, 2005, p. xix). 
Arte y dataísmo: afirmándonos desde las pantallas

Un dispositivo puede ya comunicarse con nosotros, pero esto no es posible si no es a través de la interfaz y, para esto, de las imágenes. Estas últimas se han convertido, entonces, en una síntesis de nuestro lenguaje y, a su vez, de nuestra percepción.

Afirmamos nuestro lugar en el mundo a través de las imágenes que compartimos. Dejamos la creación de nosotros mismos como subjetividades abiertas. Las imágenes que se comparten no son ya para rememorar eventos, sino para decir lo que es ahora. Hablamos con las imágenes como con las palabras para decir aquí y ahora lo que somos y no lo que fuimos.

No creemos ya totalmente en las imágenes, sino en lo que nos ha llevado hasta ellas. Son las pantallas a través de las interfaces en quienes realmente creemos, así como en los otros usuarios que comparten y permiten la dinámica de la sociedad digital. Haciendo una metáfora con la idea de creencia y fe, podemos llegar a la conclusión de que nuestras nuevas creencias son las imágenes y nuestras deidades, entonces, las pantallas y las interfaces.

Todo esto, aunque suene un poco catastrófico o, incluso, casi apocalíptico, favorece el desvanecimiento de fronteras entre disciplinas y medios, entre lo real tangible y lo real virtual. Aquí es donde la "inmaterialidad" de la imagen configura las nuevas sensibilidades, los nuevos acercamientos a las obras. Surgen nuevas estéticas, nuevas percepciones, nuevas obras. La cultura en general y nuestra forma de pensary percibir el mundo cambian, y es entonces cuando tenemos que hablar del dataísmo. Este término lo utilizó por primera vez David Brooks en 2013 en un artículo en el New York Times. Allí habló sobre la filosofía emergente de la actualidad, el poder reunir información en datos y la cultura. También mencionó eventos tan distintos como el baloncesto, la política y el lenguaje, todos relacionados con la posibilidad de entender el pasado y el presente a través de los datos.

El dataísmo asegura que nuestro valor y el valor de todas las cosas reside justamente en los datos. Recibe este nombre porque es comparado con una religión, la religión de los datos. Yval Noah Harari, en su libro Homo Deus (2017, p. 354), dice que el dataísmo por fin logra proveer: 
Una teoría general que unifica a todas las disciplinas científicas desde la musicología hasta la economía y la biología (...). Le da a todos los científicos un lenguaje común, construye puentes entre las fisuras académicas y exporta fácilmente puntos de vista entre fronteras disciplinares. Musicólogos, economistas y biólogos pueden finalmente entenderse entre ellos [traducción propia $]^{3}$.

Con estas ideas ya desarrolladas, podemos pensar que, si la interfaz es el efecto o proceso de lo que sucede en los medios, la traductora de los códigos y mensajes entre computador-humano y humano-computador, y estos códigos y mensajes son los datos o, más específicamente los metadatos de las imágenes, entonces el dataísmo involucra así a la interfaz y a las pantallas. Si, como mencionamos anteriormente, esto es una religión de datos, entonces reafirmamos la idea de que las imágenes son nuestras creencias y las pantallas e interfaces nuestras deidades.

\section{Arte e interfaz}

Para Soren Pold (2005), "la interfaz es la forma básica estética del arte digital [traducción propia]"4 (p. 1). Es, entonces, momento de hablar de las nuevas estéticas. Este término lo utilizó por primera vez James Bridle en relación con las imágenes que se acercaban a la estética del futuro, en las que incluye errores de Google Maps, errores de las computadoras, imágenes similares repetidas a través de internet e imágenes que resultan inimaginables sin la existencia del internet.

El artista siempre ha tomado una postura política con su trabajo y muchas veces ha utilizado a la imagen como su herramienta política de transformación social. Es por esto que los estudios visuales deben enfocarse a transitar entre las pantallas y la realidad. Si nuestro valor reside en los datos y estos son registrados en las interfaces, entonces podemos considerar a las nuevas estéticas junto con los datos como parte de la teoría del sistema tecnológico, digital y político desde el internet. El dataísmo se presenta, como consecuencia, no solo como una visión religiosa, sino también política desde lo cultural. 
Arte y dataísmo: afirmándonos desde las pantallas

Al construir imágenes estamos construyendo nuestra realidad. Creamos nuevos órdenes en ella y, consecuentemente, los órdenes establecidos desaparecen. El arte se vuelve la consciencia y la postura ante los nuevos contextos en donde los estudios visuales y la imagen a través de la pantalla se transforman en herramientas de resistencia para la transformación de las estructuras de poder. ¿Cómo es que el arte y nuestra percepción de ella ha cambiado? Y ¿cómo es que el arte juega un papel importante en esta idea de dataísmo y nuevas realidades?

Hoy somos las imágenes que compartimos, somos los gadgets que cargamos, somos uno mismo en distintas plataformas e interfaces, somos lo que se refleja en las interfaces. Las imágenes ya no son representaciones del mundo, son El mundo, y es el arte la disciplina que más domina el mundo de las imágenes. Si el dataísmo ha permitido que los científicos puedan comunicarse en un solo lenguaje y que las fronteras entre disciplinas hayan desaparecido, entonces es aquí, a través de este mismo "lenguaje" o "creencia", que el arte puede involucrarse con las disciplinas científicas y participar en el mundo de la cultura digital.

Con esto dicho, podemos entonces ver ahora trabajos artísticos en los que la información en datos es lo más importante. Para el usuario en la actualidad, la prioridad de la imagen reside en la información no siempre visible que esta lleva, en el lenguaje, el código o el metadato, más que en su contenido visual. Lo que le interesa al artista de hoy es cómo la imagen va "viajando a presión en lentas conexiones digitales, comprimida, reproducida, ripeada, remezclada, copiada y pegada en otros canales de distribución" (Steyerl, 2014, p. 33). Es decir, una imagen se relaciona directamente con el metadato, el hipervínculo y el hashtag, ya que son estos los que nos permiten seguir el camino que lleva la imagen como la percibimos en la actualidad. 


\section{Postura ante el mundo a través de las}

\section{pantallas}

Presento como primer ejemplo a Ryoji Ikeda, quien trabaja con números, matemáticas, datos de consumo e información transformada en imagen y analizada a través de interfaces. En su proyecto $V \neq L$ (2008) trabaja con definiciones matemáticas sobre la infinidad a través de discusiones que él tuvo con el teórico Benedict Gross. El nombre del proyecto se explica de la siguiente manera: V como el universo de von Neumann y L como el universo construible de Godel. La transformación de la información matemática es traducida en imágenes gráficas que, a pesar de que siguen siendo trabajadas con formatos numéricos (unos y ceros), se convierten en imágenes, en instalaciones, en el arte multidisciplinario per se. Como referente del trabajo de Ikeda, adjunto la dirección de su sitio web (http://www.ryojiikeda.com/).

El trabajo de Ikeda representa un primer acercamiento a lo que significa la traducción de códigos a través de la interfaz y de cómo el dataísmo abre fronteras también con el arte, pero lo que realmente nos interesa en este artículo es la postura política que se toma a partir de considerar que nuestro valor y el valor de todas las cosas está en los datos, como propone el dataísmo.

David Horvitz cuestiona y transgrede los límites del internet; con su pieza Public Access (2010), cuestiona no solamente el concepto de espacio público desde lo físico y geográfico, sino también desde el espacio en línea. Realizó un viaje por carretera a través de toda la costa de California, desde México hasta Oregon. Hizo autorretratos en todas las playas que tenían acceso público, es decir, casi toda la costa y, posteriormente, subió las fotografías en distintos artículos de Wikipedia. La idea era formar parte del archivo de domino público de cada lugar geográfico. "Estoy en estas increíbles playas, donde no hay nadie y tenía que caminar 3 kilómetros para llegar. Pero después se sube en línea al espacio digital, en donde están todos conectados. Todos están ahí, y tú no, pero lo estás [traducción propia]"5 (Horvitz, 2011). 
Arte y dataísmo: afirmándonos desde las pantallas

El trabajo de Horvitz se presenta como un cuestionamiento sobre el espacio, sobre las dinámicas en línea, sobre la autoría y la propiedad, no solamente geográfica y material, sino intelectual. Las fotografías son de dominio público y, aunque todos sabemos quién es el autor, no es lo más relevante. Estas fotografías de espacios públicos se han vuelto más públicas. Finalmente, los editores de Wikipedia bajaron las imágenes, pues consideraron que la dinámica de Horvitz era otra, que quizá se estaba promocionando y, aunque no rompía con ninguna de las reglas de Wikipedia, no les pareció que utilizara sus autorretratos para ilustrar los artículos. Se editó un libro con las imágenes y los comentarios de los editores que decidieron quitar las imágenes de internet.

En resumen, este es un claro ejemplo de lo que puede suceder en internet con las imágenes, de cómo significan mucho más de lo que podemos simplemente ver y de cómo se generan dinámicas que muchas veces no vamos a comprender o que aún ni siquiera consideramos. Estas fotografías representan una postura a través de la imagen, hacia el espacio y la propiedad, que genera una respuesta por sí sola desde las dinámicas que se generan por naturaleza en línea. Esta es una clara relación entre arte y dataísmo: el valor de las imágenes no por lo que se ha fotografiado, sino por todo lo que ha sucedido desde que se subieron en línea.

El siguiente ejemplo es algo que la mayoría de nosotros pudo presenciar recientemente. Durante la final del mundial de fútbol entre Francia y Croacia que se jugó en Rusia, en el minuto 53 apareció un grupo de personas vestidas de blanco y negro, algo similar a uniformes policiales. En televisión se observó solamente por un par de segundos, aunque la acción fue realizada en vivo y fue un acto de suma relevancia. Estas personas fueron conscientes de lo que sucedería posteriormente. Es un grupo de punk, de arte y música llamado Pussy Riot. Sabían que, a pesar de ser detenidas y de que su visibilidad en televisión sería corta, generarían una dinámica fuera de la pantalla televisiva para pasar a la pantalla de las computadoras a través de una acción tan cotidiana y sencilla como buscar en Google. 
Inmediatamente después del hecho, la publicación que habían hecho en sus redes sociales ya alcanzaba cientos y miles de lectores y de comentarios. En esta, exigían al gobierno ruso liberar a los presos políticos, poner fin a los "arrestos ilegales durante las protestas", y "permitir la competencia política en el país”. Sabían que serían más vistas en línea, no llevarían sus exigencias a la cancha, simplemente harían que el espectador se preguntara ¿qué acaba de suceder? Y, como hemos mencionado a lo largo del artículo, ¿a quién le creemos hoy en día? ¿A quién dirigimos nuestras plegarias y, en este caso, nuestras preguntas? A uno de nuestros "nuevos dioses": Google. Y, así, quienes le preguntamos a Google qué acababa de suceder en la cancha durante los últimos minutos del partido de la final mundial, entendimos lo que sucedía políticamente en Rusia y lo que hacía este grupo artístico y activista.

\section{Conclusiones}

Hablar de nuevas deidades y de que el valor de las cosas y de nuestra propia persona reside en los datos y la información que generamos puede sonar demasiado catastrófico e incluso apocalíptico, pero es justo por esta razón por la que debemos ser conscientes, como en el caso de Horvitz y Pussy Riot, del alcance de los nuevos medios, de la información y, en este caso, de la imagen.

Es necesario que tomemos una postura y que la practiquemos en esta nueva sociedad digital. Si el arte siempre ha tomado estas posturas y ha participado directa o indirectamente de la política y la economía, entonces debemos hacerlo también desde el internet a través de las pantallas. Es sumamente importante considerar a los metadatos como el archivo histórico que se está gestionando actualmente y que nosotros, no solo como artistas, sino como usuarios, estamos siendo parte de este archivo y estamos generando contenido para el mismo.

Si una publicación puede generar dinámicas y acciones, entonces trabajemos con esto para generarlas también fuera de las pantallas. Que no solamente los estudios visuales trabajen entre las pantallas y la realidad tangible, sino también nuestras acciones cotidianas, sociales $\mathrm{y}$, sobre todo, políticas. 
Arte y dataísmo: afirmándonos desde las pantallas

\section{Notas}

1 "It is my view that we can acknowledge this impact through digital art: how the interface changes what and how we see, how we experience and interact with reality and how this reality is reconfigured through the computer. Digital art in general shows us the role of the interface and the significance of the interface as an aesthetic, cultural and ideological object."

2 "Images are the interfaces that structure interaction, people, and the environments they share."

3"A single overarching theory that unifies all the scientific disciplines from musicology through economics to biology (...). It gives all scientists a common language, builds bridges over academic rifts and easily exports insights across disciplinary borders. Musicologists, economists and cell biologists can finally understand each other."

4 "The interface is the basic aesthetic form of digital art."

5 “I'm on these amazing remote beaches, there's no one there, and I had to hike two miles to get there. But then it goes up on this online space, where everyone's connected. Everyone's there, and you're not, but you are." 


\section{Referencias}

Brea, J. (2010). Las tres eras de la imagen. Madrid, España: AKAL.

Brooks, D. (4 de febrero de 2013). The philosophy of data. The New York Times. Recuperado de https://www.nytimes.com/2013/02/05/opinion/brooksthe-philosophy-of-data.html

Burnett, R. (2005). How images think. Massachusetts: MIT Press.

Harari, Y. (2017). Homo deus. Nueva York: Harper Collins Publishers.

Horvitz, D. (17 de marzo de 2011). David Horvitz talks about "Public Access"/ Entrevistadora: Lumi Tan. Recuperado de https://www.artforum.com/in terviews/david-horvitz-talks-about-public-access-27770

Ikeda, R. (2008). $V \neq L$. Recuperado de http://www.ryojiikeda.com/project/VL/

Parker, A. (10 de junio de 2011). Twitter's secret handshake. The New York Times.Recuperado de https://www.nytimes.com/2011/06/12/fashion/ hashtags-a-new-way-for-tweets-cultural-studies.html

Pold, S. (2005). "Interface realisms: The interface as aesthetic form.” Postmodern Culture, 15(2). doi:10.1353/pmc.2005.0013

Steyerl, H. (2014). Los condenados de la pantalla (Trad. M. Expósito). Buenos Aires, Argentina: Caja Negra Editora. 